\title{
COMPARISON OF LOW ALTITUDE PHOTOGRAMMETRIC METHODS FOR OBTAINING DEMS AND ORTHOIMAGES OF ARCHAEOLOGICAL SITES
}

\author{
A. T. Mozas-Calvache ${ }^{\text {a, }}$, J. L. Pérez-García ${ }^{a}$, F. J. Cardernal-Escarcena ${ }^{\text {a }}$, J. Delgado ${ }^{\text {a }}$, E. Mata-deCastro ${ }^{\text {a }}$ \\ a Dpt. Ingeniería Cartográfica, Geodésica y Fotogrametría, University of Jaén, 23071 Jaén, Spain - (antmozas, jlperez, \\ jcardena, jdelgado, emata)@ujaen.es
}

CIPA, ICOMOS and WG V/2

KEY WORDS: Cultural heritage, archaeology, comparison, TLS, DEM/DTM, orthoimage, aerial, photographs

\begin{abstract}
:
In this work it is performed a comparison of two methods for obtaining digital elevation models (DEMs) and orthoimages of medium-sized archaeological sites $\left(500-5000 \mathrm{~m}^{2}\right)$. The photogrammetric methods analyzed consist in the use of a light aerial platform applying the normal case of photogrammetry (vertical photographs and regular blocks), and the second one is based on a network of oblique photographs, taken from a telescopic mast, using a DEM obtained from a terrestrial laser scanner (TLS) survey. The main goal is to analyze the more efficient method for these studies taking into account variables such the working time, the accuracy obtained in the final products, the visual analysis of final orthoimages, etc. This study has been applied to the same archaeological site in two different epochs. The image acquisition was performed before and after a conservation intervention at the archaeological site. The results have shown similar characteristics for both products (DEMs and orthoimages) and accuracies but the density of DEMs and the visual analysis of orthoimages have shown differences that allows us to select the more adequate method taking into account the characteristics of each case. Thus the DEMs obtained using the TLS survey has shown more density of points while the visual analysis of orthoimages has shown a better behaviour (radiometrically and visually) in the case of vertical photographs.
\end{abstract}

\section{INTRODUCTION}

The realization of photogrammetric surveys of archaeological sites has been performed and applied by different methods to a great quantity of archaeological sites (with different characteristics) along the latest decades. The main goal of these methodologies is to obtain the documentation of the site. This documentation is achieving a great importance at this time. In this context the International Committee for Documentation of Cultural Heritage (CIPA) is one of the international committees of ICOMOS (International Council on Monuments and Sites) which has as main purpose the improvement of all methods for surveying of cultural monuments and sites (CIPA, 2012). A more completed study of the evolution of these applications is described by Haddad (2011) and Patias et al. (2008).

The use of light platforms for acquiring the photographs has been developed widely in these studies. The main reason is based on the conditions of these archaeological sites and the usual resolution requirements which oblige to use techniques of close range acquisition (low height of flight). These conditions limit the use of conventional planes used for lower scales' mapping. The evolution of these techniques has been a great develop, from a simple mast for raising the camera some metres to the use of unmanned aerial vehicles (UAVs). Thus, nowadays the developing of UAVs such as planes and helicopters radio-controlled and drones allow us to perform the planning of flights and their execution through the automatic guiding based on GPS/INS techniques (Eisenbeiss, 2005; Sauerbier and Eisenbeiss, 2010). In this sense a more complete study of UAVs can be found on Eisenbeiss, 2009a. The use of balloons and blimps (Altan et al., 2004; Bitelli and Girelli, 2004), kites and helikites (Verhoeven et al., 2009), masts
(Georgopoulos et al., 1999) and paragliders and ultralights (Faustmann and Palmer, 2005) as platforms for acquiring the photographs have also been used for heritage documentation and they suppose a low cost alternative with respect to those low height flights. In this way there are several works which analyze some projects developed with these techniques.

On the other hand, in the latest years the number of works which use terrestrial laser scanner (TLS) for heritage documentation have also shown an important increase. (De Felice et al., 2007; Yastikli, 2007). The main advantage of this system is based on the obtaining of a high number of points (e. g. several millions) for defining the object. Moreover, a great quantity of these works combine the use of TLS for obtaining a great resolution point cloud with the obtaining of an image or orthoimage of the site for its complete documentation (Bitelli et al. ,2007; Eisenbeiss, 2009b).

In this work, we have used two techniques which suppose a mixture of those explained previously. Thus we have used a light platform for acquiring the images of a conventional flight (vertical photographs) and we also have used oblique photographs obtained from a mast and a digital elevation model obtained from a TLS survey.

The main goal of this study is the analysis of the advantages and disadvantages of both methods and their feasibility. We also try to determinate the method more adapted to the conditions, needs and products demanded in these kinds of projects. For this purpose we must take into account the field and office works developed when applying each method and the accuracy and quality of the final products (DEMs and orthoimages).

\footnotetext{
* Corresponding author.
} 
This study has been applied to the archaeological site of Cerrillo Blanco (a burial tumulus; VIIth-Vth century BCE) located in Jaén (Spain) with an area of $2500 \mathrm{~m}^{2}$. The site, from the Tartessic epoch, has 24 single burial places and a small double megalithic tomb and includes an Iberian necropolis from the IVth-IInd centuries A.D. The two methodologies were applied in two different epochs coinciding with the previous and later periods of an archaeological intervention. The archaeological site selected presents good conditions (with respect to size, occlusions, working area, etc.) to implement and test the methods purposed.

\section{METHODOLOGY}

The methodology followed in this work is based on the application of the two different methods to be compared. The scheme of work is described in Figure 1.

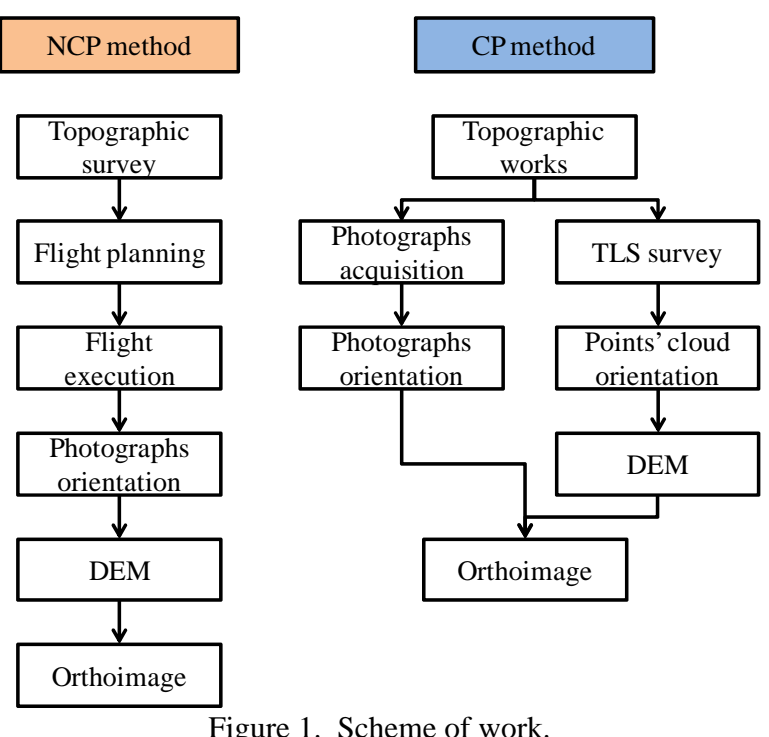

The first method (Normal Case in Photogrammetry, NCP) consists in the use of a light aerial platform under conventional photogrammetric flight conditions. In this case, we use a helium balloon which lifts a digital reflex calibrated camera suspended from a Picavet system (Picavet, 1912) allowing near vertical photographs (Figure 2). We use a system based on ropes for guiding the balloon and a system for tracking the camera poses based on a $360^{\circ}$ miniprism attached to the platform (Figure 3). The images were obtained with a $12 \mathrm{Mp}$ digital reflex camera (Canon D5 with a full frame -36 x $24 \mathrm{~mm}$ - CMOS sensor) equipped with a wide angle lens (Canon EF $24 \mathrm{~mm}$ ) with the calibration parameters known (obtained using the methodology described by Cardenal et al., 2004).



Figure 2. Helium balloon and Picavet platform (NCP case).
The coordinates of camera projection centres, previously calculated in the mission planning, are staked out in field using a robotized total station (Leica TCRA 1203) by aiming the miniprism. This miniprism only increases the platform weight by 27 gr. (Leica GRZ101 Mini Prism). The flight planning consists in a regular pattern organized in 5 strips and 80 photographs at an average $11 \mathrm{~m}$ height. The design of the photogrammetric block includes overlaps around of $70 \%$ endlap and $30 \%$ sidelap. We must take into account the possible occlusions generated by vertical walls. In this sense we recommend the execution of a previous topographic survey of the site (e. g. using GPS) in order to adapt the flight planning variables to the topographic conditions of the zone to be studied. A more completed description of this method and its application can be found in Mozas et al. (2012). The field work is completed with the situation of several targets regularly distributed all around the zone of study. Subsequently, these targets are measured with total station in order to obtain their coordinates. Finally the last stage comprises the checking of the acquired photographs in order to assure its quality and the full coverage of the site.

The office work (with a conventional DPW) includes the block triangulation, DEM extraction (using matching procedures) and edition, and the final orthoimage production (including mosaicking and radiometric adjustments). We have used software BAE System Socet Set ${ }^{\circledR}$ v5.5 for these procedures.

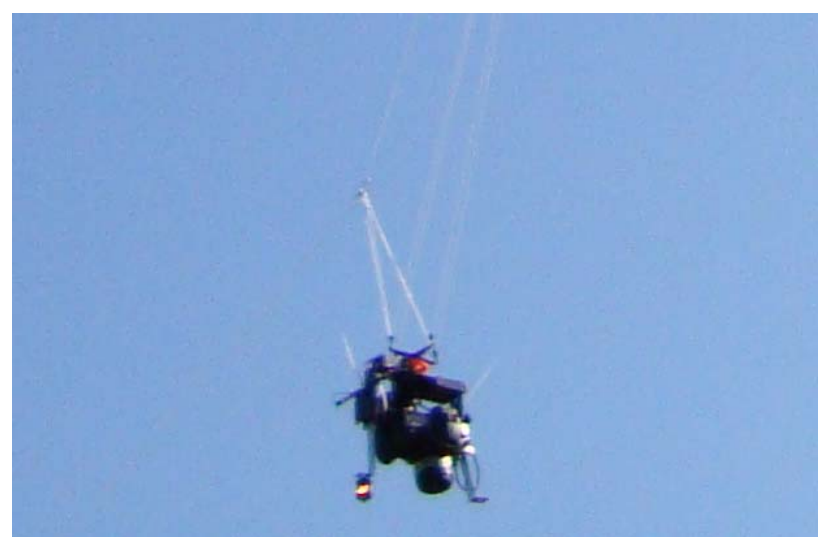

Figure 3. Detail of the platform, camera and $360^{\circ}$ Leica miniprism (NCP case).

The second method (Convergent Photogrammetry CP) consists in the acquisition of several convergent photographs from a telescopic mast situated in well-distributed camera stations which cover the site completely (Figure 4). The mast lets us to lift the camera up to $10 \mathrm{~m}$ high. The network consisted in 4 strips with 3 stations per strip. From each station at least 8 oblique photographs were taken covering $360^{\circ}$. The head of the mast was remotely controlled and the camera was connected to a tablet PC allowing remote camera control and view live. The camera and lens were the same used previously. Before the acquisition of photographs, a regular set of target is distributed along the zone of interest in order to allow the orientation process of photographs. Subsequently the targets are measured with a total station in order to obtain their three-dimensional coordinates. The distribution of targets is very important because a minimum number (at least 4 points) is necessary for each photograph. We have to note that the size of targets used in this application was equal to those used on previous method. In this case, we must take into account the importance of a full coverage of the zone of study in order to avoid zones without 
image or zones with images very inclined. This inclination problem will suppose the appearance of some zones with insufficient resolution in the final images. To avoid this problem we have to check the coverage of photographs in field, trying to minimizing the inclination of camera. This aspect is inversely related to the number of stations and the field zone acquired with one photograph but it also improves the regularity of scales between photographs. Obviously the number of stations and photographs will also increase the number of points with known coordinates which are necessaries.

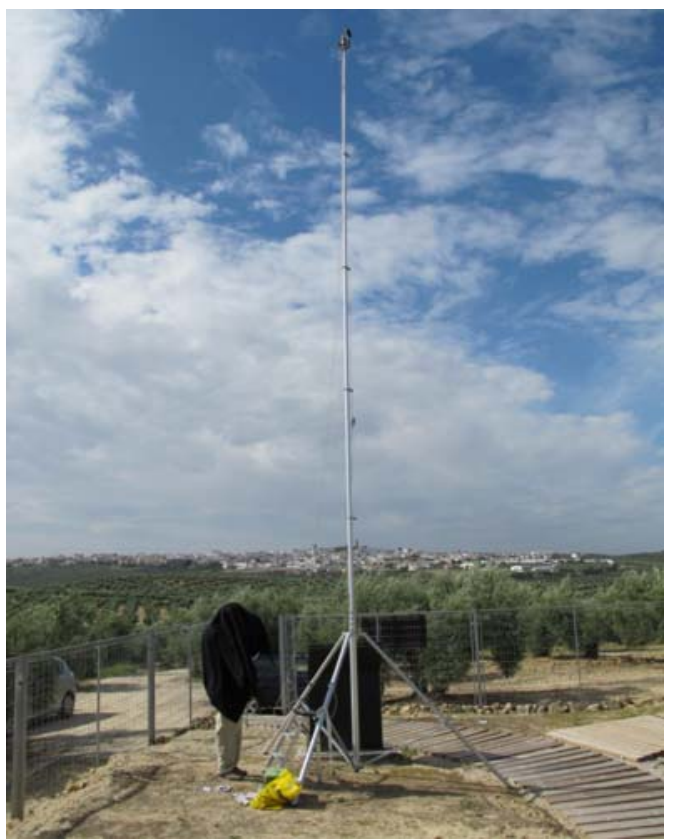

Figure 4. Telescopic mast obtaining the oblique photographs (CP case).

The field work also comprised a TLS survey to obtain the DEM of the site (Figure 5). A long range scanner (Optech ILRIS 3D) was located at high places for covering the entire site. The 3D position of each scanning place was determined using three targets with known coordinates. The field works is finished with an analysis stage of the point clouds in order to check if we have obtained the full coverage of the archaeological site. The office work included the image block triangulation (without stereo viewing), TLS point clouds registration and merging, DEM edition and orthoimage generation. These procedures were performed using software Maptek i-Site ${ }^{\circledR} \mathrm{V}$ 3.3 and BAE System Socet ${ }^{\circledR}$ Set v5.5.

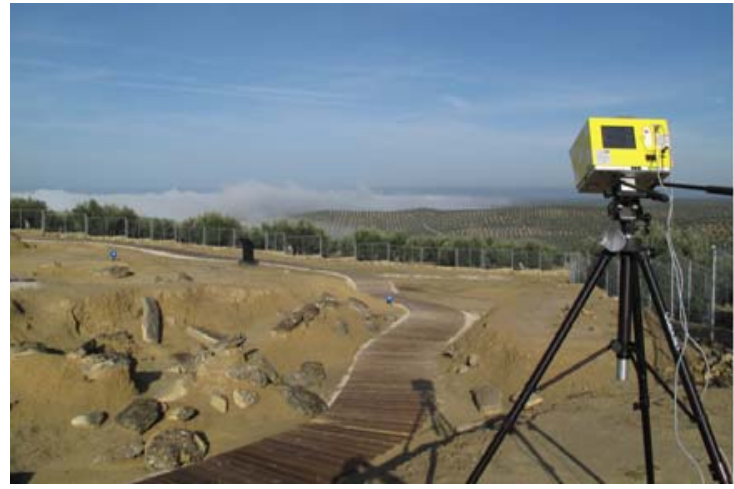

Figure 5. Optech ILRIS 3D TLS used for DEM acquisition (CP case).

\section{RESULTS}

The analysis of the results obtained from the application of both methodologies is performed attending some qualitative and quantitative variables such the working time (field and office), the accuracy of the final products and the visual appearance of orthoimages.
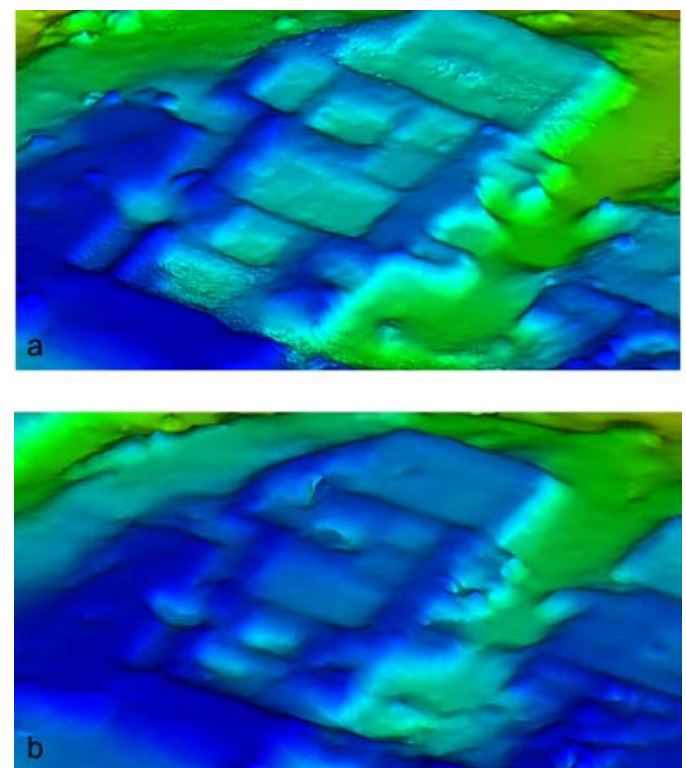

Figure 6. Views of surfaces obtained from DEMs: a) NCP case; b) CP case.

The analysis of the working time have shown that the method NCP requires a longer planning time because the need of a previous topographic survey of the zone and a higher number of operators for guiding the balloon and performing the photographs (3-4 operators). However the method CP can be executed by only 2 operators. The weather conditions are also more restrictive, especially with respect to wind conditions, when using the balloon (NCP). On the other hand, the office work is higher in the case of CP method because there is not possibility of stereo viewing and the time consuming edition procedures. The cost is also related to the price of the instruments used for implement each methodology. Obviously the method $\mathrm{CP}$ requires a more expensive instrument than the method NCP (TLS cost).

The number of photographs was higher for method CP with respect to NCP (104 vs 80 photographs). This difference was due to the need of guarantee the full coverage of the site. In NCP case this guaranty is achieved following the flight planning. In the case of method $\mathrm{CP}$, we had to extend the number of photographs in order to guarantee this condition.

In general, the final results were very similar for both NCP and $\mathrm{CP}$ methods. These similar results are obtained because we have planned all the variables implicated (scale of photographs, etc.) in order to obtain similar products to be compared. In this way we have obtained similar accuracies of DEMs (RMS $<0.06 \mathrm{~m}$ ) (Figure 6). The main difference is the higher density of the TLS DEM, whose edition was more difficult and time consuming. This is due to the fact that we do not have the possibility of using stereo edition in this case (we do not have stereoscopic pairs of photographs). The orthoimages also presented similar characteristics $(2 \mathrm{~cm}$ resolution) and accuracies (RMS $<0.02 \mathrm{~m}$ ) (Figure 7). 

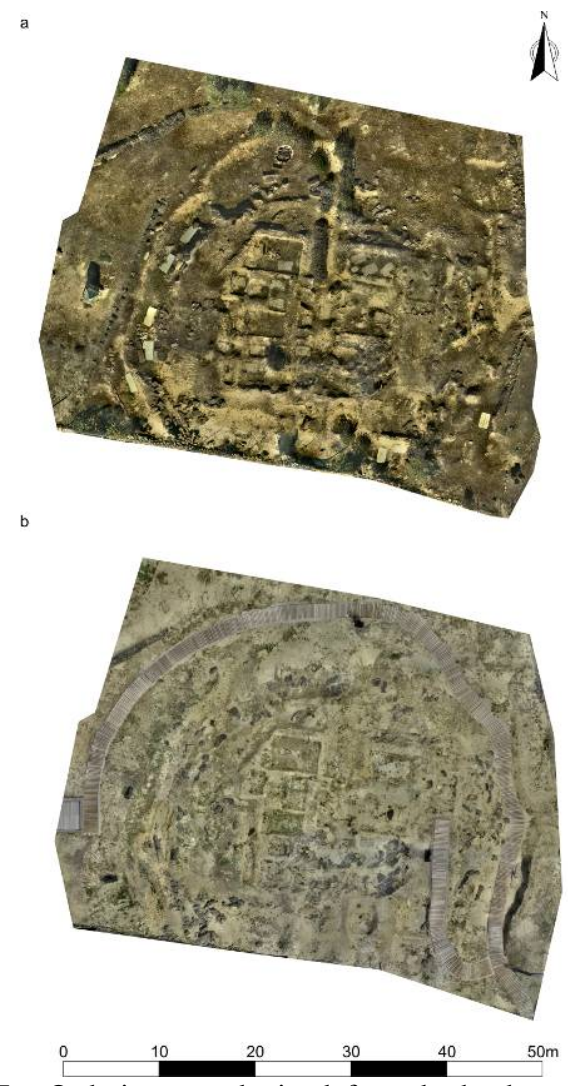

Figure 7. Orthoimages obtained from both photogrammetric surveys: a) NCP case; b) CP case.

The results of the visual analysis of the orthoimages are commented below. First of all, we have to note that the visual difference between the tones of the orthoimages shown in Figure 7 is caused by the cleaning works performed in archaeological intervention. These works mainly consisted on the extraction of the accumulated vegetation.

a

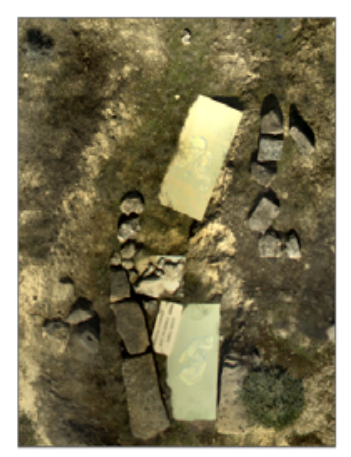

Figure 8. Detailed of zones with ghost and stretched images into CP orthoimage: a) NCP case; b) CP case.

The visual analysis in detail shows higher ghost and stretched images in CP case (Figure 8), mainly caused by the tilt photographs, requiring more edition than NCP case. The method NCP also gives more homogeneous radiometric values, lower occlusions and homogenous photo-scale. The variability of radiometric values in CP case is caused by the illumination changes originated by the variable orientation of camera with respect to the sun. In this sense, we have to note that the photographs were acquired in periods of time with the best illumination conditions and the photographs were acquired as vertical as it was possible in order to minimize these problems.

\section{CONCLUSIONS}

As conclusion, both methods are feasible for photogrammetric surveys at these archaeological sites. The selection of the method to be applied will depend on the available equipment and the field conditions.

On an equal basis, we suggest the use of the NCP method because the facilities of edition with stereo viewing and the reduction of the number of photographs. On the other hand, the difficulties for guiding and controlling the helium balloon caused by wind conditions suggest the use of other UAVs for this acquisition. Anyway the vertical photographs gives better radiometry and scale conditions. This is an important factor in order to obtain an improvement in orthoimages. The guiding of the platform supposes an important issue in this case due to the need of guarantee the full coverage of the site. This aspect is achieved using the new systems for guiding UAVs based on GPS/INS techniques or using methodologies for guiding such as the one explained in this paper.

So we suggest the use of the convergent photogrammetric method in cases where the use of normal case is not possible, for example due to the presence of obstacles. In this case we have to take into account important issues such as the full coverage of the zone, the presence of obstacles, the acquisition of photographs as vertical as possible, the scale of photographs, the final resolution of the orthoimage (GSD), etc.

However, if it is feasible to obtain a reliable and high density TLS DEM, we can propose a hybrid approach which uses the NCP method for image recording and TLS for DEM. In this case the edition of this DEM can be easier because we have stereo viewing. In this way the TLS is considered a basis DEM to be edited stereographically. Anyway the high density TLS DEM is another important product in order to obtain a full documentation of the archaeological site and it must constitute a basic feature for documenting these sites.

\section{REFERENCES}

Altan M. O., Celikoyan T. M., Kemper G., Toz G., 2004. Balloon photogrammetry for cultural heritage. In Geo-Imagery Bridging Continents. In: Proceedings of the XXth ISPRS Congress. Istanbul, Turkey, Vol. XXXV, Part V, pp. 964-968.

Bitelli, G., Girelli, V. A., 2004. Low-height aerial imagery and digital photogrammetrical processing for archaeological mapping. In: International Archives of Photogrammetry, Remote Sensing and Spatial Sciences, Istanbul, Turkey, Vol. XXXV, Part B5, pp. 498-504.

Bitelli, G., Girelli, V. A., Remondino, F., Vittuari, L., 2007. The potential of 3D techniques for Cultural Heritage object documentation. In: Proceedings of Videometrics, San Jose, USA, Vol. 6491.

Cardenal F. J., Mata E., Castro P., Delgado J., Hernández M. A., Pérez J. L., Ramos M., Torres M., 2004. Evaluation of a digital non metric camera (Canon D30) for the photogrammetric recording of historical buildings. In: 
International Archives of Photogrammetry, Remote Sensing and Spatial Information Sciences, Istanbul, Turkey, Vol. XXXV, Part B5, pp. 564-569.

De Felice, G., Mangialardi, N. M., Sibilano, M. G., Volpe, G., 2007. Late Roman villa at Faragola (Foggia, Italy). Laser scanning for a global documentation methodology during field research. In: Proceedings of the 35th International Conference on Computer Applications and Quantitative Methods in Archaeology (CAA), Berlin, Germany.

Eisenbeiss, H., 2005. Applications of photogrammetric processing using an autonomous model helicopter. In: Proceedings of the XX CIPA Symposium, Torino, Italy, pp. 1-6.

Eisenbeiss, H., 2009. UAV Photogrammetry. PhD dissertation, Institute of Geodesy and Photogrammetry, Zurich, Switzerland.

Eisenbeiss, H., 2009. A Model Helicopter Over Pinchango Alto: Comparison of Terrestrial Laser Scanning and Aerial Photogrammetry. New Technologies for Archaeology, Natural Science in Archaeology. M. Reindel, G.A. Wagner (eds.). Springer-Verlag Berlin Heidelberg, Berlin, Germany, pp. 339358.

Faustmann, A., Palmer, R., 2005. Wings over Armenia: use of a paramotor for archaeological aerial survey. Antiquity, 79(304), pp. 402-410.

Georgopoulos, A., Karras, G. E., Makris, G.N., 1999. The photogrammetric survey of a prehistoric site undergoing removal. The Photogrammetric Record, 16(93), pp. 443-56.

Haddad, N. A., 2011. From ground surveying to 3D laser scanner: A review of techniques used for spatial documentation of historic sites. Journal of King Saud University - Engineering Sciences, 23, pp. 109-118.

International Committee for Documentation of Cultural Heritage (CIPA), 2012. CIPA website. http://cipa.icomos.org (April 2012)

Mozas, A. T., Pérez, J. L., Cardenal, F. J., Mata, E., Delgado, J., 2012. Method for photogrammetric surveying of archaeological sites with light aerial platforms. Journal of Archaeological Science, 39(2), pp. 521-530.

Patias, P. Grussenmeyer, P., Hanke, K. (2008). Applications in Cultural Heritage Documentation, in: Li, Chen y Baltsavias (Eds.), Advances in Photogrammtery, Remote Sensing and Spatial Information Sciences: ISPRS Congress Book, CRC Press, Taylor and Francis Gr., London, UK, pp. 363-383.

Picavet PL., 1912. Suspension pendulaire elliptique. La Revue du cerf-volant.

Sauerbier, M., Eisenbeiss, H., 2010. UAVs for the documentation of archaeological excavations. In: International Archives of Photogrammetry, Remote Sensing and Spatial Information Sciences, Newcastle, UK, Vol. 38, Part V, pp. 526531.

Verhoeven, G., Loenders, J., Vermeulen, F., Docter, R., 2009. Helikite aerial photography -a versatile means of unmanned, radio controlled, low-altitude aerial archaeology. Archaeological Prospection, 16 (2), pp. 125-138.
Yastikli, N., 2007. Documentation of cultural heritage using digital photogrammetry and laser scanning. Journal of Cultural Heritage, 8, pp. 423-427.

\section{ACKNOWLEDGEMENTS}

The present study has been financed by grant TIN2009-09939 (IFOTEL Project) from the Ministry of Science and Innovation, National Programme R+D+I, 2008-2011, European Regional Development Funds (ERDF) and TEP-213 Research Group (PAIDI, Junta de Andalucía). 